\title{
Turning Philosophy with a Speculative Lathe: Object Oriented Ontology, Carpentry, and Design Fiction
}

\author{
LINDLEY Joseph ${ }^{\mathrm{a}}$; COULTON Paul ${ }^{\mathrm{a}}$ and AKMAL Haider ${ }^{\mathrm{a}}$ \\ a Imagination, Lancaster University \\ * Corresponding author e-mail: j.lindley@lancaster.ac.uk \\ doi: 10.21606/dma.2017.327
}

\begin{abstract}
Arising from the complex relationship between their physical affordances, digital shadows, and interconnections, the things which make up the 'Internet of Things' (the IOT) present designers, users, and society at large, with a range of unique and as-yetunfamiliar forms of network-contingent agency. These new design spaces engender new forms network anxiety, that in turn can result in a range of ill effects including overstimulation, information overload, and paranoia. Contemporary philosophies of technology provide a theoretical base with which designers can temper these emergent techno-anxieties with a sort of scholarly comfort blanket, however, closing the loop between such theories and design practice so that one explicitly informs the other remains a rarely-tackled and elusive challenge within design research. To help explore how designers may underpin their practice with philosophical foundations, in this paper we recount our own experience of conducting an loT-based Speculative Design project. This research attempts to encode, enact, and express ideas derived from a contemporary philosophical movement-Object Oriented Ontology (000)and 'Carpenter' those ideas into designed artefacts using the Design Fiction as World Building approach to Speculative Design. To 'turn' a physical material-wood, metal or plastic-means reshaping the material with a lathe to afford it a tangible elegance and grace. Metaphorically speaking, in this paper, 000 is our material and Design Fiction is our lathe, we reflect on the process of sculpting and carving theory, lending shape and poise to $\mathrm{OOO}$ through Design Fiction enabled Carpentry.
\end{abstract}

Internet of Things; Object Oriented Ontology; Speculative Design; Design Fiction.

\section{Introduction}

Design and technology shape and change both us and our world. Designers, the things they design, and the people who interact with those things, are instruments of rhetoric (Buchanan, 1985) and are mutually influential, together shaping the world (Silverstone, 2006; Stam \& Eggink, 2014a). This holds true across many domains and contexts, with examples including industrial design (Lockton,

1. This work is licensed under a Creative Commons Attribution-NonCommercial-Share Alike 4.0 International License.

2. https://creativecommons.org/licenses/by-nc-sa/4.0/ 
Harrison, \& Stanton, 2010), design of services or platforms (Stam \& Eggink, 2014b), and even areas such as video game design (Coulton, Burnett, $\&$ Gradinar, 2016). By attempting to understand the nature of this reciprocity between designers, users and things, the social construction of technology-which can be cast in various lights such as domestication (Silverstone, 2006), mediation (Verbeek, 2015), or emerging lenses like 'open script' (Stam \& Eggink, 2014a, 2014b)-is a key driver of the Philosophy of Technology's so-called 'empirical turn' (Brey, 2010). Theories contributing to this empirical turn reject pessimistic-by-default and dogmatically-deterministic perspectives, and rather than referring to capital-T 'Technology' as a universal phenomenon refocus their interests on specific technologies and/or use contexts. Given the pervasion of technology through society during the late $20^{\text {th }}$ century it was perhaps inevitable that pragmatic and empirically reinforced theories, equipped to differentiate between disparate technologies and contexts, also emerged in this period. During the $21^{\text {st }}$ century technologies and the profundity of their impact on society have become even more ubiquitous. This ubiquity of effect brings with it, as Brey points out, the need for supplemental theories which help us make sense of a landscape that changes ever-quicker:

"To better understand human-technology relations, we need theories of the interaction between technological artifacts and practices on the one hand, and human perception, cognition, action, experience, identity, body image, moral development, moral deliberation, human nature, basic beliefs and values, and so forth. Without such theories, either developed within philosophy or borrowed from the social sciences, we can make little progress in understanding and evaluating human-technology relations." (Brey, 2010)

The merits and necessity of this empirical turn notwithstanding, bridging the space between theoryderived insights and the messy tangibility of design practice - to take a so-called practical turn -is not straightforward. To explore aspects of this practical turn, within the context of the empirical turn, is the principle aim of this paper. We achieve this by using Speculative Design to enact and give form to Object Oriented Ontology (OOO)-a new materialist branch of metaphysics (which is, perhaps, in an ironic ascendency, given the Philosophy of Technology's relatively recent conveyance towards empiricism). Irony aside, within the domain that the design practice this research has emerged from (the loT) OOO's rejection of 'correlationism' (Gratton \& Ennis, 2014) and proposed 'flat ontology' (Bryant, 2011) seem to be useful means to theoretically present the loT's networkand-data contingent 'constellations' of agency and meaning (Lindley, Coulton, \& Cooper, 2017). We build on the $\mathrm{OOO}$ thesis and mediate the challenge of the practice-theory gap by experimenting with 'Carpentry' - a kind of "philosophical lab equipment" (2012). Put simply, Carpentry is "making things that explain how things make their world" (ibid). The process we describe in this paper, then, is about making 'Speculative loT things' whose purpose is to explain how 'loT things' make the 'IoT world'. While the work is based on insights gleaned from an loT research project, the main contribution of this paper is not about the loT itself, but rather the intention is to provide generally applicable insights about how to give shape, form and poise to theory-in this case OOO-by using Speculative Design.

The paper is organised as follows. First, we provide additional background with an introduction to $\mathrm{OOO}$ and Speculative Design. Then, we explore the design space of our case study, describing the IoT and then discussing contemporary loT design issues. Next, we provide a reflexive account of how we brought these constructs together in a design process, detailing the designs themselves. Finally, we reflect on what we have learned about enacting and shaping 000 by using Speculative Design to inform future design practice.

\section{Object Oriented Ontology}

As we are not philosophers we willingly defer the task of arguing OOO's validity and/or critiquing its merits to those more qualified than ourselves. However, what follows aims to articulate an 
accessible summary of our interpretation of $\mathrm{OOO}$ and to contextualise the subsequent account of the interplay between our design practice and our engagement with theory.

In his seminal work Being and Time, Heidegger presents his view of ontology. By providing the foundations for $\mathrm{OOO}$ this highly influential $20^{\text {th }}$ century philosophical text has taken on a new life in the $21^{\text {st }}$ century (Harman, 2002). The traditional Heideggerian view argues that things-objects-are all but impossible to understand in their own phenomenological terms, and therefore, we should make sense of them in relation to human use. Heidegger coined neologisms to communicate his argument, and famously uses a hammer as an example. When a hammer (or other object) is in its normal context of use it is 'ready-to-hand' and if that context is disturbed (for example if the head of the hammer falls off) then it is described as 'present-at-hand'. The metaphysics of this distinction are complex and must be negotiated outside of this paper, but the important point to note is that the hammer only comes into being via a human use (or perhaps non-use, in the case of the broken hammer). Central to the Heideggerian position is the notion that existence is a "correlate between [the human] mind and world" (Bogost, 2012). That these two constructs are inseparably linked is what Meillassoux refers to as 'correlationism' (Gratton \& Ennis, 2014). O0O rejects this notion of correlationism and instead entertains the idea that objects have their own realities which are distinct from human use. From this post-correlationist position, anything-literally any thing, from a fibre optic cable, to a blade of grass, to a quantum computer, to a gooseberry fool-may be cast in the limelight of its own ontological resolve. If we consider the amalgamated glow that emanates from the bazillions of tiny lights-of-non-correlationism then the resulting luminescence is what illuminates the tundra of OOO's so-called "flat ontology" (Bryant, 2011). Having departed from familiar and intuitive human-centric ontologies, the vantage point one must adopt when considering the nature of OOO's flat ontology is a strange and conflicted place to stand:

"In short, all things equally exist, yet they do not exist equally [...] This maxim may seem like a tautology-or just a gag. It's certainly not the sort of qualified, reasoned, handwrung ontological position that's customary in philosophy. But such an extreme take is required for the curious garden of things to flow. Consider it a thought experiment, as all speculation must be: what if we shed all criteria whatsoever and simply hold that everything exits, even things that don't? [...] none's existence fundamentally different from another, none more primary nor more original." (Bogost, 2012, p. 11)

This open-endedness is necessary because in 000 the scope of the term 'object' is not limited to material things, but extends to include any given idea or construct. Such a categorisation requires special appreciation, and a theory which allows for multiple types of 'Being' to meaningfully coexist. Exemplifying this Bogost uses the famously ill-fated video game E.T. the Extra-Terrestrial as an example. He muses that E.T.s object, is in fact simultaneously many different things:

- 8 kilobytes of opcodes

- a compilation of source into assembly code

- a flow of radio frequency into a television

- a plastic cartridge

- memory etched on wafer

- a consumer good

- a set of rules and game mechanics

- intellectual property

- 'the worst game ever made'

- a constituent of 728,000 Atari games buried in New Mexico ${ }^{1}$

- all of the above

${ }^{1}$ cf. https://en.wikipedia.org/wiki/E.T._the_Extra-Terrestrial_(video_game) 
There is no elementary unit which comprises the video game, it is never a single one of the objects above, nor is it their conglomerate. Bogost tells us Latour refers to this as 'irreduction' -or the idea that no single thing can be truncated to another. Irreduction's consequence is that, in most cases, inter-object relations are devoid of intimacy or mutual-knowing. Being for different objects is usually uniquely distinct and thus "objects only unlock each other's realities to a certain extent" (Harman, 2002). Although this notion is challenging even when considering the objects we are most familiar with-those known as homo sapiens - this view of ontology is evocative, powerful, and represents an enticing philosophical renaissance; "the epistemological tide ebbed, revealing the iridescent shells of realism they had so long occluded" (Bogost, 2012).

\subsection{Carpentry}

Beyond a shared rejection of correlationism there is much disagreement between OOO's scholars. Our interpretation aligns with that Bogost presents in Alien Phenomenology (2012). Of particular influence is the notion of Carpentry; the practice of creating "machines" that attempt to reveal clues about the phenomenology of objects. While it's accepted that objects' experiences can never be fully or intimately understood, the machines of Carpentry act as proxies for the unknowable. They proffer a "rendering satisfactory enough to allow the artifact's operator to gain some insights into an alien thing's perspective" (Bogost, 2012, p. 100). A range of examples are cited some of which are created as deliberate acts of Carpentry whilst others simply demonstrate the properties of Carpentry serendipitously. One of Bogost's examples is software to visualise how a 90s games console stores and constructs sprites and palettes using the finite memory available, the result is a unique view on the connection between the 'raw' versions of the image-perhaps closer to how the computer and software might see things - and the game as we see it on the screen (ibid). Another example, the Latour Litanizer ${ }^{2}$, is a carpentered machine which queries Wikipedia, calls upon the random article feature, extracts the article title, repeats, and then presents a number of these randomly extracted titles as a list. While its instrumental purpose is to quickly and easily generate Latour-like litanies, it also provides a portal of sorts into the interior reality of Wikipedia's content: "Not only does the diversity and detachment of being intensify with each fresh litany, but those very qualities also invite further discussion of the object in question at Wikipedia" (2012, p. 96).

Whether achieved by leveraging computer code or some other craft "through the making of things we do philosophy" (Wakkary et al., 2017) - that is the essence of Carpentry. Wakkary et al. do their Carpentry through material speculations (ibid), and while Bogost sees himself as a philosopherprogrammer, he notes that philosopher-chefs, philosopher-astronomers, and philosophermechanics are all uniquely equipped as Carpenters in their own right. In our case, we are exploring the practicalities of being, and the possibilities for, philosopher-designers. Couching 000 in some kind of applied practice is, in fact, the process by which it is lent a concrete legitimacy that other branches of metaphysics often evade. Hence, material engagements with 000 are what make the theory compelling, and Carpentry is the process by which that engagement happens:

"If a physician is someone who practices medicine, perhaps a metaphysician ought be someone who practices ontology. Just as one would likely not trust a doctor who had only read and written journal articles about medicine to explain the particular curiosities of one's body, so one ought not trust a metaphysician who had only read and written books about the nature of the universe." (Bogost, 2012, p. 91)

Having realised that computers have, by virtue of the programming languages we've created to tame them, relatively accessible inner worlds, Bogost uses computing as a compelling context to practice Carpentry. There is some shared ground between Bogost's computer-centric approach to $\mathrm{OOO}$ and the way which we used Design Fiction in this work. We might say that computer programmers, emboldened by the ultimate control code has over the computer, allows them to

\footnotetext{
${ }^{2}$ http://bogost.com/writing/blog/latour_litanizer/
} 
'play God' (within the realm of the computer or system they happen to be programming). This demiurgic gift affords the philosopher-programmer a great deal of freedom to explore the objects of the computer realm (including the computer itself). As we discuss below, a similar quality is afforded when designers unshackle themselves from the preconceptions of contemporaneous truths of reality, and, with this freedom practice Speculative Design.

\section{Speculative Design and Design Fiction}

Design usually seeks to answer questions, and thus to create futures. Speculative design, in contrast, uses design to asks questions about possible futures ${ }^{3}$. Hence the family of approaches which we collectively refer to as Speculative Design do not aim to create a products for sale, or that necessarily solve a problem, rather they are design processes intended to elicit thought and provoke deeper understandings about whatever design space they address (Auger, 2013; Dunne, 2006; Dunne \& Raby, 2013). There are many nuanced views on the Speculative Design landscape which are beyond the scope of what we can address in this paper ${ }^{4}$ however the specific method of speculation we employ is Design Fiction.

There are a number of concurrent yet incongruent perspectives on what Design Fiction is; these disagreements with discussions about the most productive ways to create and use the practice. The school of thought referred to as Design Fiction as World Building (Coulton, Lindley, Sturdee, \& Stead, 2017) most exactly describes the approach we adopt in this work. The World Building approach argues that Design Fiction is the creation of multiple artefacts that, when viewed together, describe the coordinates of, or 'entry points' into, a fictional world (ibid). As well as providing points of entry, these artefacts tend to depict aspects of that world at different scales. So, a given constituent artefact of a Design Fiction may either represent a large area of the world (providing a 'zoomed out' summary view), or a smaller area (providing a 'zoomed in' detail view).
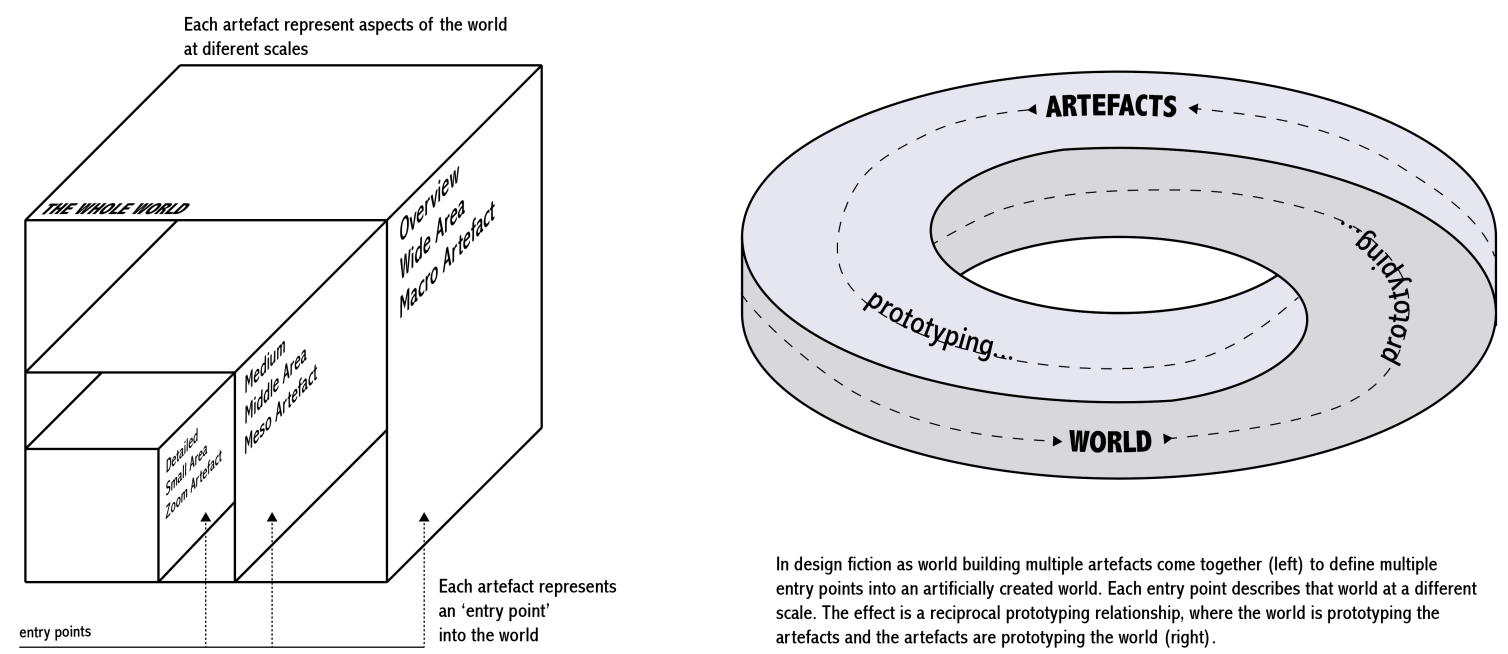

In design fiction as world building multiple artefacts come together (left) to define multiple entry points into an artificially created world. Each entry point describes that world at a different scale. The effect is a reciprocal prototyping relationship, where the world is prototyping the artefacts and the artefacts are prototyping the world (right).

Figure 1. Visualising how multiple artefacts construct a fictional world and how this fosters a reciprocal prototyping relationship with the artefacts.

By creating multi-scaled worlds like this, Design Fictions produce a reciprocal prototyping relationship. The artefacts define the contours of the fictional world and simultaneously prototype

\footnotetext{
${ }^{3}$ Although more couched in the related practice of critical design, this asking/answering contrast is summed up nicely in "A/B" (Raby \& Dunne, 2009)

${ }^{4}$ For an overview, disambiguation, and exposition of Speculative Design's internal we recommend reading Dunne \& Raby (2013) and Tonkinwise's review of the same text (2014).
} 
the nature of that world; meanwhile, the world that emerges from the artefacts reciprocates and prototypes the contextualised properties of those artefacts (ibid). We also suggest that both the individual artefacts, and the whole Design Fiction world, may be seen in terms of Bogostian Carpentry. Returning briefly to the notion of a programmer-philosopher playing God by manipulating computer code, the same logic plays out with Design Fiction but rather than the subroutines, APIs and procedure calls that the programmer-philosopher might utilise, a Design Fiction-philosopher has the texture and contours of the artificial world-and the design of the artefacts that define those attributes-at their creative disposal.

\section{The Internet of Things}

The term 'IoT' probably emerged from a presentation given by Kevin Ashton ${ }^{5}$ in the late 1990s. Ashton was a pioneer of RFID and saw it as one of the technologies that would facilitate the realisation of a future akin to Mark Weiser's 'ubiquitous computing' vision (1999). Reflecting on his coining of the term Ashton notes "If we had computers that knew everything there was to know about things-using data they gathered without any help from us-we would be able to track and count everything, and greatly reduce waste, loss and cost" (2009). Today 'the' loT is in fact many related concepts and is defined variously depending on the interests and motivations of the person making the definition. Popular tropes include technologically driven explanations like Ashton's original RFID-centric vision) and application-domain driven visions (e.g. loT for healthcare, transport, or manufacturing). Ultimately, reductionist attempts to define the loT are somewhat futile as it is the implications of loT adoption that carries with it challenges, opportunities and risks (cf. Lindley, Coulton, \& Sturdee, 2017). Notwithstanding the gamut of possible meanings for the term loT, this research is part of an loT-centric research project specifically interested in consumer-grade, domestic and home-based loT devices and/or services.

Connected loT products in our homes have a brief but chequered history. In recent years product manufacturers, spurred on by new market opportunities and the increasing accessibility and affordability of the hardware necessary to connect devices to the internet, have brought to market vast arrays of familiar-looking devices, but with somewhat unfamiliar loT-enabled attributes. From toothbrushes to hair brushes; televisions to lightbulbs; washing machines to ovens; cameras to consoles; juicers to socks; kettles to t-shirts; health trackers to sex toys-the diversity of domestic loT products is already extensive and continues to grow.

Amidst this variety of products there are many examples of innovative and novel designssometimes with distinguishable benefits over their unconnected counterparts-however issues with domestic loT products have also come to the fore. For example, the television manufacturer Vizio was reprimanded for producing televisions that, without appropriate permissions or consent, gathered data pertaining to customers television watching habits ${ }^{6}$ which the manufacturer then went on to sell for marketing purposes (Barrett, 2012). Other issues result from the fact that many IoT products rely on cloud services to function. This has potential unintended consequence that if the devices have been designed to be dependent on the cloud, and if these services go offline for some reason, it leaves customers with semi-functioning or worse, useless, hardware such as occurred in recent years with Nest's Revolv hub and Pebble smartwatches. Perhaps the most pertinent issue around the loT, is security. In a 2016 attack an array of loT devices from various manufacturers were breached, then updated to run malware, before being utilised in a distributed denial of service (or DDOS) attack which caused web services including Netflix, Twitter and Airbnb to become temporarily unavailable. Although high profile because of its visibility and scale, this is but

\footnotetext{
${ }^{5}$ https://en.wikipedia.org/wiki/Kevin_Ashton

${ }^{6}$ These practices are, in fact, commonplace in modern televisions. Vizio received disproportionate coverage because details of their data collection were omitted from the user agreement.
} 
one of many similar attacks which are made possible by the most basic of security oversights, particularly prevalent in emerging loT contexts. Exemplifying a great many issues in a single product/service, the toy doll My Friend Cayla was ultimately banned in Germany due to meeting the legal criteria of a digital surveillance device (Oltermann, 2017). Contributing to this legal classification are a litany of design flaws: its lack of security could expose child users' to malevolent hackers; the privacy policy seems to provision for the possibility that recordings of child voices being utilised for unknown purposes by unknown third parties; the doll relies on an already-unsupported cloud system, and hence despite still being on sale from various retailers may be 'broken out of the box' (Moye, 2015).

As we begin to share our homes with the loT, and transpose open aspects of our private space to the far flung reaches of the Internet, personal, societal and commercial impacts abound. Pierce and DiSalvo explore some aspects of the loT's advance into our homes with visual metaphors, and ultimately reflect on the "anxiety, exhaustion, overstimulation, overload, paranoia, unease, distrust, fear, and creepiness" - or what they collectively refer to as network anxiety (2017) - that has so far come hand-in-hand with the loT. Emerging design research stances-from Animism's objects-withsouls (Van Allen, McVeigh-Schultz, Brown, Kim, \& Lara, 2013) to thing ethnography (Giaccardi, Cila, Speed, \& Caldwell, 2016) - are unified by an awareness of this anxiety, and respond with varying theoretical foundations. Arguably the advent of $\mathrm{OOO}$, as one of these new materialist perspectives, is also driven by the desire to facilitate our understanding of the new ways of Being that emerge as we adopt technologies like the loT. Of course, these responses are not confined to academia, philosophy, or design. For example, the EU's General Data Protection Regulations ${ }^{7}$ (GDPR) is reflective of a Europe-wide realisation that loT devices and the data they generate have the ability to impact upon citizens in terms of their most basic of rights.

GDPR is the specific design space around which the project we recount here was centred. The work aimed to take into account the unique properties of networked services and devices in the loT, whilst responding to the yet-to-be-tested GDPR, and the fundamental ethical and rights-based contentions which underpin it. We do this, specifically, by invoking Bogostian Carpentry, which, in turn, is achieved by utilising Design Fiction as World Building.

\section{Designing the loT Around Meaningful Consent (or, 'By Reading This Title You Agree to Positively Review This Paper')}

In the following we describe our journey through the design process. In order to better explain the context of our design space, however, first we review some of the GDPR's protections and make comparisons to established practices in the design of digital systems. Although legal interpretations are so far untested in courts the articles of the GDPR theoretically protect the right:

- To be aware what personal data is held about an individual;

- To access any personal data that is held;

- To rectify inaccurate personal data that is held;

- To data portability (i.e. to extract data in a readable form to be taken elsewhere);

- To refuse permission for processing or profiling of personal data;

- That any consent obtained relating to personal data must be verifiable, specific, unambiguous and freely given.

The apparatus of consent (i.e. how information is presented to users, and how that consent is recorded) is the problem area that became of particular interest to us. Although some progress has been made recently, for example pre-ticked checkboxes and non-consensual cookie usage were both outlawed in Europe in $2011^{8}$, inappropriate apparatus for users to indicate they have, understood,

\footnotetext{
${ }^{7}$ http://www.eugdpr.org/article-summaries.html

${ }^{8}$ http://www.bbc.co.uk/news/world-europe-15260748
} 
and agree to conditions of use - for example a long body of text followed by an 'I agree' tick boxare still the norm. There are fundamental problems with this approach, the most obvious being that while pre-GDPR laws assume a tick in a box as legal consent, in practice it is very rare that users actually have read the terms, and even less so that they have understood them. Crudely but vividly demonstrating how such mechanisms are not an effective way to gain meaningful consent, a 2016 study found that of people who agreed to terms, only $25 \%$ of participants looked at the agreement at all, and only $2 \%$ could demonstrate reasonable comprehension (Obar \& Oeldorf-Hirsch, 2016). One-size-fits-all approaches, whereby user agreements are written in such a way as to obtain all the permission the device or system could ever need, structurally remove the ability for users to be selective about which features of a system they actually want to use, and thus denies them the GDPR protection for 'specific unambiguous' consent. These systems also tend to fail to account for temporality meaningfully; once consent has been given it is often difficult, and sometimes impossible, to revoke all or part of it at a later date.

\subsection{Carpentering a Design Fiction World}

Prior to directly considering how we might approach Carpentry we began the process by determining and shaping the entry points to our Design Fiction world. We elected to make this a product-led Design Fiction; focusing on a single product-an loT door lock-which would act as a fulcrum, around which other aspects of the Design Fiction coalesce. Inspired by loT locks that already exist on the market ${ }^{9}$ the fictional lock has the following features:

- Keyless opening using NFC;

- Geofencing (automatically lock/unlock depending on user's location);

- Providing guests temporary access via smartphone;

- Voice activation (via a voice agent such as Amazon Echo);

- Interfacing with other services (via integrative platforms such as IFTTT).

In terms of the design problem, each of the lock system's features requires a subtly different relationship with collected data, where data is stored, and how it is processed. Keyless opening using NFC operation only requires that data be stored within the user's own network; geofencing requires that data be processed by the lock company; and voice activation or services such as IFTTT could lead to data being shared with any number of $3^{\text {rd }}$ parties. Given that the Design Fiction's primary concern was GDPR, we opted to give technical implementation only cursory consideration and working around the assumption the lock is activated, via a hub, by an loT radio standard such as ZigBee and that suitable APIs facilitate integration with external services such as IFTTT.

${ }^{9}$ cf. http://uk.pcmag.com/surveillance-cameras/77460/guide/the-best-smart-locks-of-2017 


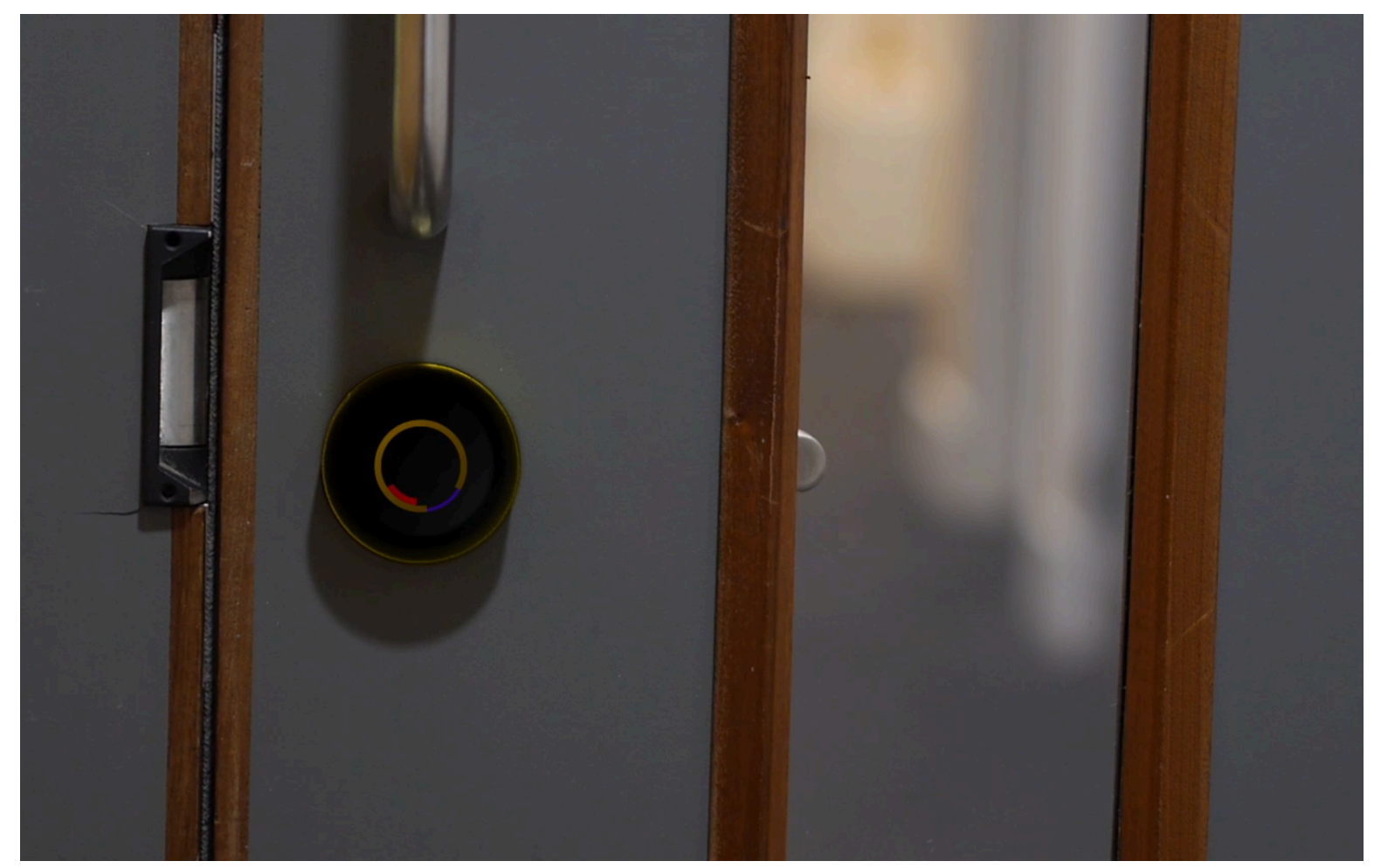

Figure 2. Still from supporting video showing the simple lock design. The electronics are housed in this plate which would replace one side of the standard lock plate with the remainder of the lock mechanism remaining the same.

With the basis of the Design Fiction established the task was consider how we might 'do' Carpentry. Extrapolating backwards from central issue we were concerned with (ethical and rights-based concerns related to personal data in the domestic loT) and attempting to consider what 'unit operations' should act as basecamp for our expedition into $00 \mathrm{O}^{10}$. Immediately it is obvious that whilst human object and the device object are, of course, relevant, it is the data object(s) that appear central to the issues here; they are the containers and carriers for the information to which we attach ethical and moral significance. With this in mind our experiments with Carpentry began by trying to understand what it is to ' $\mathrm{Be}$ ' among the data. While it is generated from the material world we live in, once captured by sensors and processed by silicon chips the data is no longer of our world. We began by appropriating network analysis software Wireshark ${ }^{11}$ for use as a Carpenter's tool, to explore the otherworldly nature of the network and data.

10 'Units' and 'unit operations' are Bogost's terms for individual objects within what Levi Bryant calls 'mereology' and Latour cites as 'irreduction' - that any given object is simultaneously its own thing and inevitably part of another object too, e.g. an loT lock is part of the door object, the house object, and the network object, and the lock object itself (Bogost, 2012, p. 22)

${ }^{11}$ https://www.wireshark.org/ 


$\begin{array}{llllllllllllllll}01 & 00 & 5 e & 7 f & f f & f a & 94 & 10 & 3 e & 3 e & 66 & \text { e9 } & 08 & 00 & 45 & 00 \\ 00 & 91 & 00 & 00 & 40 & 00 & 04 & 11 & 2 b & 0 e & c 0 & \text { a8 } & 9 a & \text { ab } & \text { ef } & \text { ff } \\ \text { ff } & \text { fa } & 0 \mathrm{c} & 03 & 07 & 6 \mathrm{c} & 00 & 7 \mathrm{~d} & \text { ee } & 3 \mathrm{~b} & 4 \mathrm{~d} & 2 \mathrm{~d} & 53 & 45 & 41 & 52 \\ 43 & 48 & 20 & 2 a & 20 & 48 & 54 & 54 & 50 & 2 \mathrm{f} & 31 & 2 \mathrm{e} & 31 & 0 \mathrm{~d} & 0 \mathrm{a} & 48 \\ 4 \mathrm{f} & 53 & 54 & 3 a & 20 & 32 & 33 & 39 & 2 \mathrm{e} & 32 & 35 & 35 & 2 \mathrm{e} & 32 & 35 & 35 \\ 2 \mathrm{e} & 32 & 35 & 30 & 3 a & 31 & 39 & 30 & 30 & 0 \mathrm{~d} & 0 \mathrm{a} & 4 \mathrm{~d} & 41 & 4 \mathrm{e} & 3 \mathrm{a} & 20 \\ 22 & 73 & 73 & 64 & 70 & 3 a & 64 & 69 & 73 & 63 & 6 \mathrm{f} & 76 & 65 & 72 & 22 & 0 \mathrm{~d} \\ 0 \mathrm{a} & 4 \mathrm{~d} & 58 & 3 a & 20 & 32 & 0 \mathrm{~d} & 0 \mathrm{a} & 53 & 54 & 3 a & 20 & 75 & 72 & 6 \mathrm{e} & 3 a \\ 42 & 65 & 6 \mathrm{c} & 6 \mathrm{~b} & 69 & 6 \mathrm{e} & 3 \mathrm{a} & 73 & 65 & 72 & 76 & 69 & 63 & 65 & 3 a & 62 \\ 61 & 73 & 69 & 63 & 65 & 76 & 65 & 6 e & 74 & 3 a & 31 & 0 \mathrm{~d} & 0 \mathrm{a} & 0 \mathrm{~d} & 0 \mathrm{a} & \end{array}$

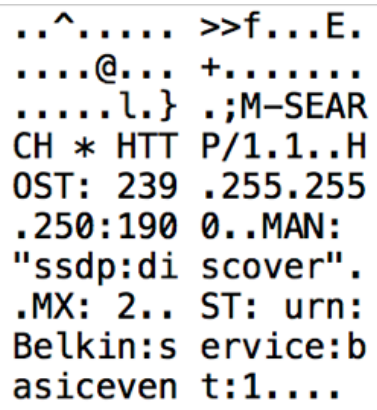

Figure 3. This is a 'packet' of data that an loT device broadcasts on whatever network it is attached to, essentially saying "hello" to the network so that it can be discovered by any devices it needs to talk to.

Wireshark is a network protocol analyser, allowing an unadulterated view of data as it is moved around computer networks. We applied Wireshark to a private network with various loT devices attached to it. Beyond the volume of network traffic (over 3000 individual packets of data going to/from a single computer on a network with only a handful of devices in under 15 seconds) one of the most striking things we noted when looking at data packets as 000 unit operators was the similarity between them. Packets are dissected into hexadecimal code and metadata, and hence trying to imagine the network hardware's phenomenology, it may be rather like a postman's; although packets are clearly packets, and the metadata is visible (i.e. address), a qualitative assessment of its contents simply isn't possible within the system's architecture. The same is true on the Internet, and while it may seem obvious, this very simple application of the Carpenter's mind-set hints that there is likely no purely technological solution to the problem of GDPR-compliant personal data and privacy, because, vis-à-vis the network's own tiny ontology, there is no problem: there are only data to identify, process, and ultimately deliver to the right recipient. Ideas like data protection and GDPR are human concerns. They have no gravity to the computer, network, or data objects.

If we move away from the digital space, traverse the flat ontology, and adopt the more familiar human lens, we might ask "How would I decide whether this system's data policy is private enough to be acceptable to me?". Whilst Human-Centred Design techniques such as ethnography, activity analysis, focus groups or co-design (cf. Giacomin, 2014) could be used to try and elicit generalizable insights about human attitudes to data, humanity's penchant for context may confound attempts to find a happy medium representing the 'right' way to interpret GDPR (schraefel, Gomer, Alan, Gerding, \& Maple, 2017). This problem of ultimately particular context dovetails directly with our OOO-derived perspective in that we wouldn't expect multiple examples of human objects to necessarily have shared values.

Having noted these two extremes (context-driven value judgements on the human side, and the arbitrary delivery of data packets on the computation side) our consideration of how to connect the two led us to develop a map metaphor. If we take the Lake District National Park ${ }^{12}$ as an object, whilst it is possible for a human object to understand its phenomenology in some small way by, for example, visiting the park, the Lake District's reality can also be accessed by reading a map of the area. The map can be seen as a form of Carpentry, it mediates a relationship between objects that otherwise have very little in common (i.e. the National Park and a human being reading the map) even if they are physically in different places and have never encountered each other. Similarly, mapping-as-Carpentry like this could mediate between humans and ecosystems where data a native inhabitant.

Initial attempts to construct maps for this purpose were fraught with difficulties arising from how complex potential data-relationships are, even in relatively straightforward loT systems. Figure 4 illustrates a data scenario around an loT door lock which has been configured to trigger smart

12 https://en.wikipedia.org/wiki/Lake_District 
lighting to turn on when the user unlocks the door. While the cause and effect are straightforward and visible to the user (opening the door results in the lights coming on), there are in fact at least three cloud services behind the scenes making the hardware work, and as shown in this example there may be unknown $3^{\text {rd }}$ parties also using the data. To translate this into a static map that absolutely and concretely details where data goes and when, in an accessible manner, is not practical. Confounding the already difficult task, our human appreciation of context makes the challenge even harder. To cartographically represent, or respond, to each human object's understanding of context-specific 'acceptability' (i.e. when it is okay to share data and when it is not okay) is something that needs to be done on a case-by-case basis (schraefel et al., 2017).

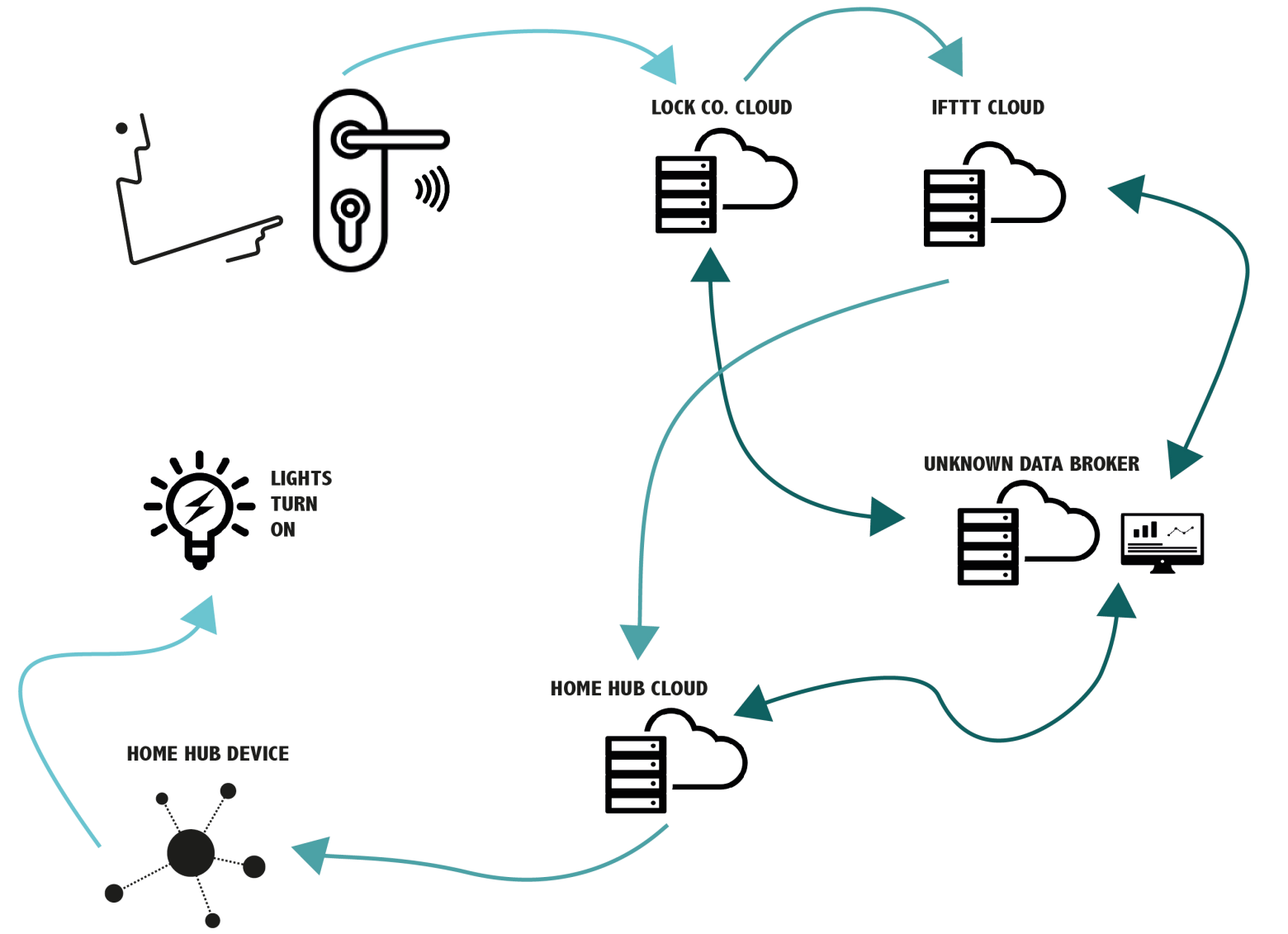

Figure 4. Triggered by the user unlocking a door data flows across and is processed on different networks and does not necessarily have a specific end point.

To resolve our mapping-misgivings we needed to make two compromises, and although this changes the nature of the design space it does not hamper our enquiry's overall aim to explore practice and philosophy. First, we reduced the scope of our interest from a very general notion around 'GDPR compliance' to the specificity of 'personal identifiability' (based on data). Second, we had to reject the wholly deterministic view that our exploration of data packets brought, and instead build a map with the ability to communicate aspects of context, risk, and probability. Hence, it turned out that the path our exploration with 000 took, was wholly different to what we had initially expected. We anticipated that exploring the tiny ontologies of the loT lock itself, the data it produces, and its users, would lead us toward Carpentry applicable to one of those objects, what actually happened is that we arrived at an artefact of Carpentry around an entirely new object-one that communicates the likelihood of identifiability - and whose own tiny ontology, offers a new way to view any specific assemblage of devices, services, data, and people. By communicating the chance that a person could be identifiable based on the data associated with device use, and presenting that in terms of whether the data is held on devices owned by a user, servers owned by companies the user knows, 
or servers owned by 'anyone else', we aimed to have defined a construct that could represent both sides of the human/computer dichotomy that 000 helped us comprehend.

The most basic forms of the identifiability maps which reflect notions of risk and probability, are shown in figure 5. Due to some metaphorical and visual similarity to the Bohr model of the hydrogen atom ${ }^{13}$ we have referred to these as 'Orbits', or Identifiability Orbits. These maps represent data that is generated, stored and processed as part of an loT system, and specifically where that data is held. A circular band represents each 'level' of data and our key privacy construct of identifiability is communicated by how sharp or blurry the edge of that level is. Hence, if the circle is the middle is has a clearly defined edge, it is almost definite that the user could be identified by the data at that level. The blurrier the edge of any level is, the less likely it is that a user could be identified.
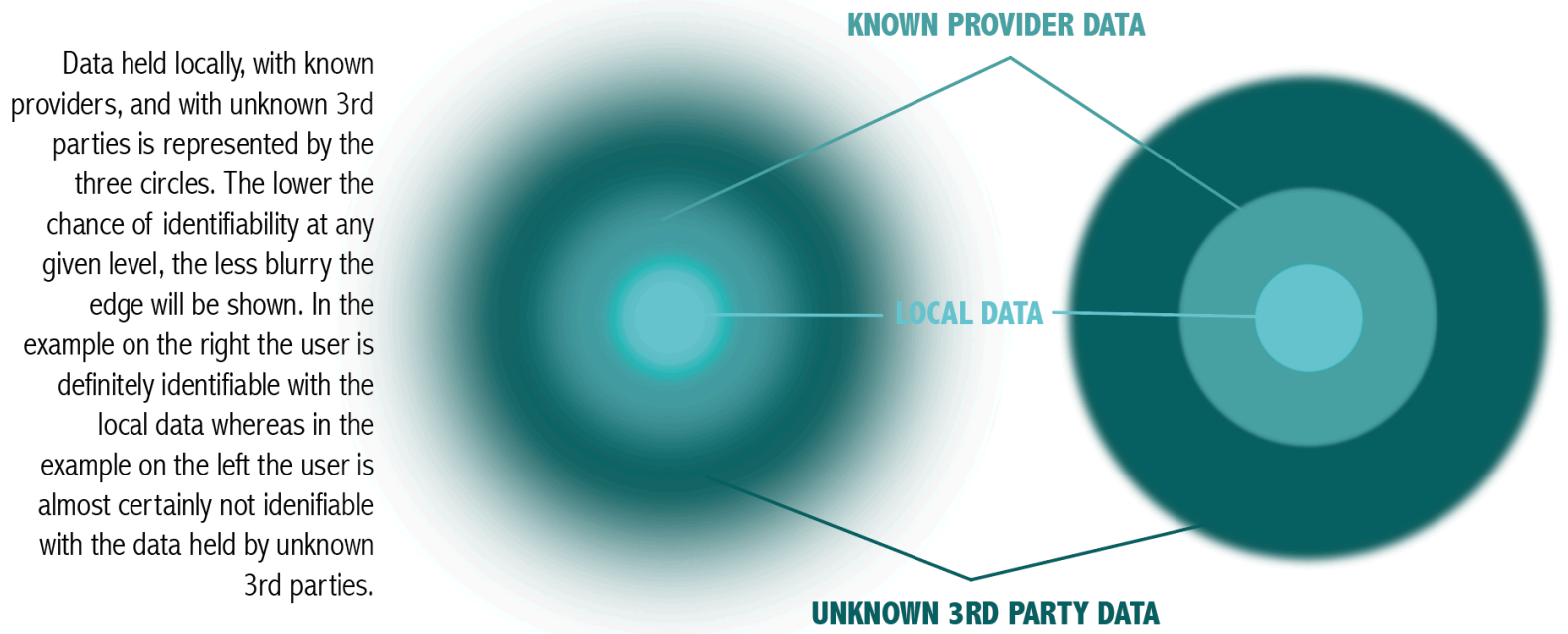

Figure 5. Early prototype design for identifiability Orbits.

Exploring how the design might be implemented in software, and how a user might interact with it, we implanted the Identifiability Orbits into our Design Fiction world by creating a film that depicts a user adding a lock to their smart home. The interaction in our film is triggered by instructing a voice agent to detect new devices; once the lock is detected the home's, the voice agent instructs the user to use the supporting 'Orbit Privacy App' on the user's phone so they can configure their privacy settings. By using a slider, the various functions of the lock can be enabled or disabled, and the data implications of those choices visualised using an Identifiability orbit.

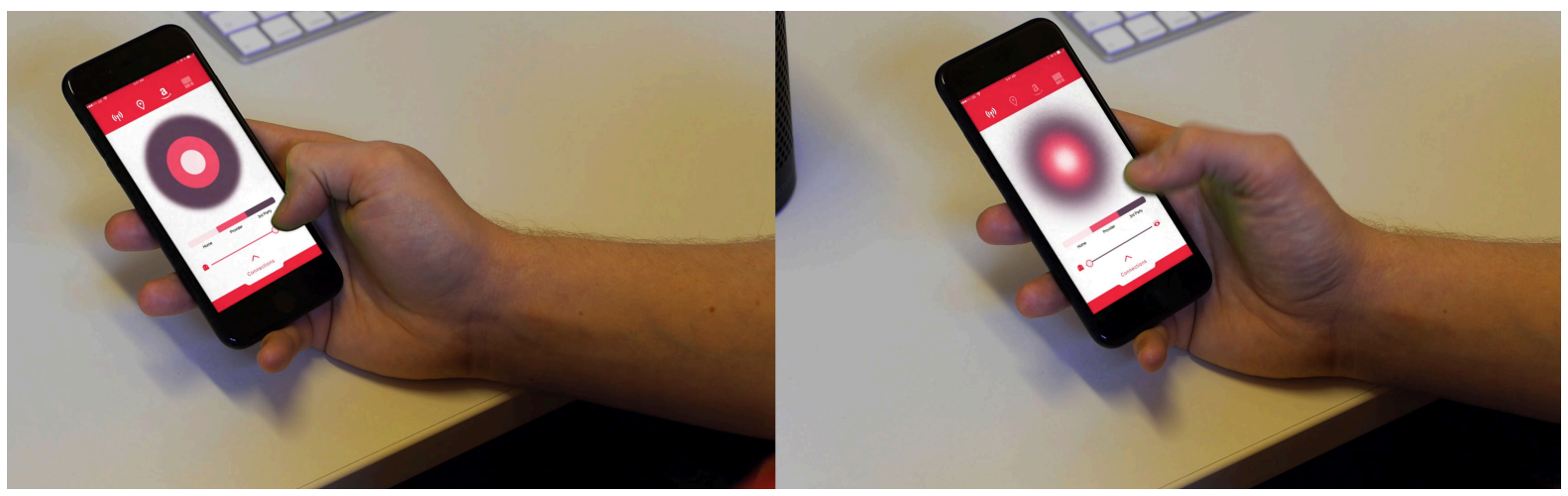

Figure 6. Stills from the Design Fiction film. A user uses the Orbit-based privacy app to configure which functions their loT lock will have permission to use. On the left they have enabled maximum functionality, Orbit updates to show that the user will most likely be identifiable at all levels, although that is not certain with third parties. The inverse is shown on the right.

${ }^{13}$ https://en.wikipedia.org/wiki/Bohr_model 
With the basic interaction demonstrated the film proceeds to demonstrate how a user may use such an app to dynamically modify their choices (figure 6). In our scenario, the user originally configured their lock for maximum privacy. The scenario extends to show that, if notified by a delivery company who require access to the house, the Orbit app communicates to the user identifiability implications of the data flow associated with provisioning temporary access to the delivery company, before revoking it again once delivery is completed. Although this work was completed before it was announced this is a data flow very reminiscent of what is being proposed to support Amazon Key ${ }^{14}$.

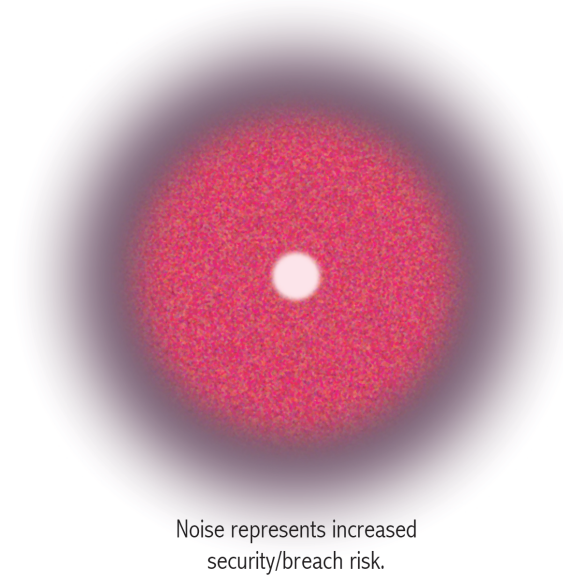

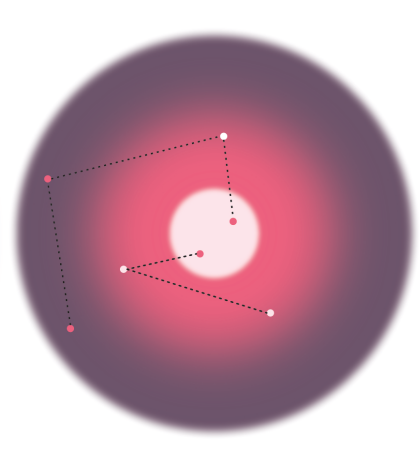

Specific data resulting from events (e.g. 'lock open' or 'user registration').

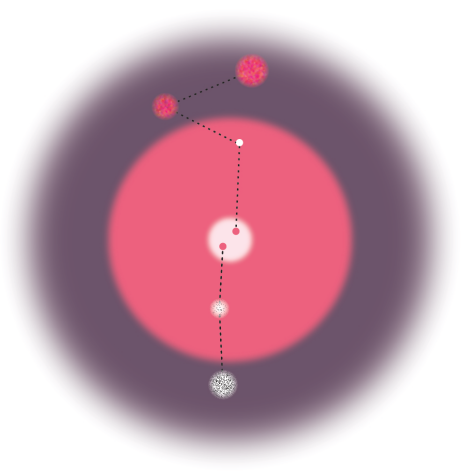

Noise within data points relates to the relative security/breach risk at that level.

Figure 7. Prototype designs extending the core Orbit concept to communication richer information.

While this project explores how Design Fiction Carpentry is viable means to attempt to do 000, it's worth noting the Orbit maps have some merit as a design proposal in their own right. If such a system were to be implemented specific areas that we identified for development include moving beyond the identifiability compromise and understanding how to augment the maps to include richer information (see figure 7), and on an operational level, understanding what background research would be necessary to create meaningfully-populated Orbits in the first place. However, these questions of implementation go beyond the scope of the academic enquiry we present here.

\section{Concluding Reflections}

Responding to the emerging network anxieties associated with our increasingly connected world, in this research we unpack and apply 000 in order to shed light on design's intersection with philosophy. The case we draw is focused on the loT's physical presence in our homes combined with its mostly-unseen data shadow, and the risks arising from how data flows, is processed, and has agency. Legislative responses such as GDPR are intended to protect citizens from these risks, and whilst contemporary scholarship has sought theories to conceptually contain these new complexities with a range of theories, including $\mathrm{OOO}$, this research explores the practicalities of injecting this theory into design practice.

We are not philosophers and thus we acknowledge that this paper is built from our interpretation of OOO-heavily reliant on Bogost's Alien Phenomenology (2012), which itself is but a single scholar's take on a theory that is the subject of disagreement even among its proponents-and it is therefore likely other scholars' perspectives may be subtly or considerably contrast with ours! Whilst we do not argue that designers must incorporate theory into practice, our belief is that we've demonstrated that by recognising a synergy between the qualities this particular theory and the challenges we sought to address, $\mathrm{OOO}$ was demonstrably a generative and analytical tool to help

\footnotetext{
${ }^{14}$ https://www.theverge.com/2017/10/25/16538834/amazon-key-in-home-delivery-unlockdoor-prime-cloud-cam-smart-lock
} 
understand the design context, and as such played a central role in both deconstructing the problem but also in assembling possible solutions.

To adeptly respond to the rafts of previously unknown technologically-driven challenges we collectively face, design's methods and metaphors need to be reimagined, invigorated and bootstrapped. Exemplified by the Orbit prototypes, this thesis is intended to be taken as an indicative example of how design researchers may dissect similar challenges, ultimately in pursuit of contemporarily-apt approaches. While the Orbits appear to be viable early design concepts, our main contribution with this work is to demonstrate how to turn OOO's metaphysics-to make 000 tangible through Design Fiction. Reflecting on this process it seems that 000 , performed in this way, has the potential to change the nature of the design space to which it is applied in the first place; in our case by arriving, unexpectedly, at a place where the Orbit concept emerged as a means to communicate aspects of data policies in a meaningful and potentially GDPR-compliant manner. Although extending from a relatively tightly scoped study, we suggest that to develop design methods apt for the modern world, design researchers may viably use Design Fiction as World Building to practically engage philosophies such as 000 , in the process helping to progress understanding of how design intersects with theory, as well as arriving at rewarding and useful design outcomes.

Acknowledgements: We would like to extend our gratitude and thanks to the anonymous reviewers of this paper for their useful and constructive comments as well as our colleagues at Imagination Lancaster. This research has been made possible through the support of the RCUK Cyber Security for the Internet of Things Research Hub PETRAS (petrashub.org) under EPSRC grant EP/N02334X/1.

\section{References}

Ashton, K. (2009). That "Internet of Things" Thing. Retrieved Octobe 5, 2017, from http://www.rfidjournal.com/articles/view?4986

Auger, J. (2013). Speculative design: crafting the speculation. Digital Creativity, 24(1), 11-35. https://doi.org/10.1080/14626268.2013.767276

Barrett, B. (2012). How To Stop Your Smart TV From Spying on You | WIRED. Retrieved September 11, 2017, from https://www.wired.com/2017/02/smart-tv-spying-vizio-settlement/

Bogost, I. (2012). Alien phenomenology, or, what it's like to be a thing. U of Minnesota Press.

Brey, P. (2010). Philosophy of Technology after the Empirical Turn. Techné: Research in Philosophy and Technology, 14(1), 36-48. https://doi.org/10.5840/techne20101416

Bryant, L. R. (2011). Democracy of Objects. Open Humanities Press. https://doi.org/10.3998/ohp.9750134.0001.001

Buchanan, R. (1985). Declaration by design: Rhetoric, argument, and demonstration in design practice. Design Issues, 2(1), 4-22. https://doi.org/10.2307/1511524

Coulton, P., Burnett, D., \& Gradinar, A. (2016). Games as Speculative Design: Allowing Players to Consider Alternate Presents and Plausible Futures. In Proceedings of the 50th Design Research Society Conference (pp. 1-17).

Coulton, P., Lindley, J., Sturdee, M., \& Stead, M. (2017). Design Fiction as World Building. In Proceedings of the 3nd Biennial Research Through Design Conference. Edinburgh, UK.

Dunne, A. (2006). Hertzian Tales: Electronic Products, Aesthetic Experience, and Critical Design. The MIT Press.

Dunne, A., \& Raby, F. (2013). Speculative Everything. London: The MIT Press.

Giaccardi, E., Cila, N., Speed, C., \& Caldwell, M. (2016). Thing Ethnography. In Proceedings of the 2016 ACM Conference on Designing Interactive Systems - DIS '16 (pp. 377-387). https://doi.org/10.1145/2901790.2901905 
Giacomin, J. (2014). What is human centred design? Design Journal, 17(4), 606-623.

https://doi.org/10.2752/175630614X14056185480186

Gratton, P., \& Ennis, P. J. (2014). The Meillassoux Dictionary. Edinburgh University Press.

Harman, G. (2002). Tool-being: Heidegger and the metaphysics of objects. Open Court Publishing.

Lindley, J., Coulton, P., \& Cooper, R. (2017). Why the Internet of Things needs Object Orientated Ontology. The Design Journal, 20(sup1), S2846-S2857. https://doi.org/10.1080/14606925.2017.1352796

Lindley, J., Coulton, P., \& Sturdee, M. (2017). Implications for Adoption. In Proceedings of the $2017 \mathrm{CHI}$ Conference on Human Factors in Computing Systems. https://doi.org/10.1145/3025453.3025742

Lockton, D., Harrison, D., \& Stanton, N. A. (2010). The Design with Intent Method: A design tool for influencing user behaviour. Applied Ergonomics, 41(3), 382-392. https://doi.org/10.1016/j.apergo.2009.09.001

Moye, D. (2015). Talking Doll Cayla Hacked To Spew Filthy Things (UPDATE) | HuffPost. Retrieved September 11, 2017, from http://www.huffingtonpost.com/2015/02/09/my-friend-cayla-hacked_n_6647046.html

Obar, J. A., \& Oeldorf-Hirsch, A. (2016). The Biggest Lie on the Internet: Ignoring the Privacy Policies and Terms of Service Policies of Social Networking Services. In The 44th Research Conference on Communication, Information and Internet Policy. https://doi.org/10.2139/ssrn.2757465

Oltermann, P. (2017). German parents told to destroy doll that can spy on children. Retrieved August 3, 2017, from https://www.theguardian.com/world/2017/feb/17/german-parents-told-to-destroy-my-friendcayla-doll-spy-on-children

Pierce, J., \& DiSalvo, C. (2017). Dark Clouds, lo \$\#! +, and ? [ Crystal Ball Emoji ]: Projecting Network Anxieties with Alternative Design Metaphors. DIS '17 Proceedings of the 2017 Conference on Designing Interactive Systems, 1383-1393. https://doi.org/10.1145/3064663.3064795

Raby, F., \& Dunne, A. (2009). A/B. Retrieved October 27, 2014, from http://www.dunneandraby.co.uk/content/projects/476/0

schraefel, m. c., Gomer, R., Alan, A., Gerding, E., \& Maple, C. (2017). The Internet of Things: Interaction Challenges to Meaningful Consent at Scale. Interactions, 24(6), 26-33. https://doi.org/10.1145/3149025

Silverstone, R. (2006). Domesticating domestication. Reflecting on the life of a concept. In T. Berker, M. Hartmann, Y. Punie, \& K. Ward (Eds.), Domestication Of Media And Technology (pp. 229-247). Open University Press.

Stam, L., \& Eggink, W. (2014a). How to Interest People for the Hare instead of the Chase, An exploration of open script design to change consumer behaviour. In Proceedings of the annual Design Research Society conference (DRS). Umea, Sweden.

Stam, L., \& Eggink, W. (2014b). Why Designers and Philosophers should meet in school. In Proceedings of the E\&PDE 2014 16th International conference on Engineering and Product Design, University of Twente, The Netherlands.

Tonkinwise, C. (2014). How We Intend to Future Review of Anthony Dunne. Design Philosophy Papers, 12(2), 169-187. https://doi.org/10.2752/144871314X14159818597676

Van Allen, P., McVeigh-Schultz, J., Brown, B., Kim, H. M., \& Lara, D. (2013). AniThings: Animism and Heterogeneous Multiplicity. In CHI '13 Extended Abstracts on Human Factors in Computing Systems on CHIEA'13 (p. 2247). https://doi.org/10.1145/2468356.2468746

Verbeek, P. (2015). Beyond Interaction: A Short Introduction to Mediation Theory. Interactions ACM, 26-31. https://doi.org/http://doi.acm.org/10.1145/2751314

Wakkary, R., Oogjes, D., Hauser, S., Lin, H., Cao, C., Ma, L., \& Duel, T. (2017). Morse Things: A Design Inquiry into the Gap Between Things and Us. Proceedings of the 2017 Conference on Designing Interactive Systems, 503-514. https://doi.org/10.1145/3064663.3064734

Weiser, M. (1999). The computer for the 21 st century. ACM SIGMOBILE Mobile Computing and Communications Review, 3(3), 3-11. https://doi.org/10.1145/329124.329126 
About the Authors:

Joseph Lindley is a postdoctoral researcher applying his doctoral research into Design Fiction as part of the PETRAS Cyber Security for the Internet of Things Research Hub.

Paul Coulton is the Chair of Speculative and Game Design at Lancaster University's exploratory design-led research lab, Imagination.

Haider Akmal is an artist and doctoral research student at Lancaster University employing Speculative Design methods to explore the Internet of Things. 